\title{
Evaluation of biodegradation and biocompatibility of collagen/chitosan/alkaline phosphatase biopolymeric membranes
}

\author{
E BERTEANU ${ }^{1}$, D IONITA ${ }^{2, *}$, M SIMOIU ${ }^{3}$, M PARASCHIV ${ }^{1}$, R TATIA ${ }^{1}$, A APATEAN ${ }^{1}$, \\ M SIDOROFF $^{1}$ and L TCACENCO ${ }^{1}$ \\ ${ }^{1}$ National Institute of Research and Development for Biological Sciences, Bucharest 060031, Romania \\ ${ }^{2}$ Politehnica Bucharest University, Faculty of Applied Chemistry and Material Science, \\ Department of General Chemistry, Bucharest 011061, Romania \\ ${ }^{3}$ National Institute of Infectious Diseases-Prof. Dr. Matei Bals, Bucharest 021105, Romania
}

MS received 23 September 2015; accepted 29 October 2015

\begin{abstract}
The aim of this study was to develop a new variant of membranes based on collagen (COL), chitosan (CHI) and alkaline phosphatase (ALP) immobilized and cross-linking with glutaraldehyde (GA) at different concentrations. The biodegradation in the presence of collagenase was investigated. Biocompatibility was evaluated by MTT assay using a mouse fibroblast cell culture type NCTC (clone 929). Non-cross-linked samples were biocompatible and membranes cross-linked with low concentrations of GA $(0.04,0.08 \%)$ were also biocompatible. However, high concentrations of GA lead to a decreased biocompatibility. The adsorption behaviour of $\mathrm{Ca}^{2+}$ ions to all membranes were evaluated using the Freundlich isotherms. Haemolytic studies were performed in order to consider their applications in biomineralization process. By the addition of collagen and ALP to chitosan, the haemolytic index decreases, the COL-CHI-ALP membrane being in the non-haemolytic domain, while the COL-CHI-ALP-GA membrane has a haemolytic index greater than 2 , and is slightly haemolytic.
\end{abstract}

Keywords. Collagen; chitosan; biocompatibility; adsorption.

\section{Introduction}

Immobilization of biomolecules on biopolymeric supports is relevant in many areas of biomaterial research. In recent times, a 2-step immobilization procedure was developed for the facile conjugation of biomolecules onto various surfaces using self-polymerization of dopamine into polydopamine [1].

Over the past decade, there has been tremendous progress in developing advanced biomaterials for tissue repair and regeneration. For example, chitosan-based materials have a wide range of applications, including in wound dressings, cartilage and bone grafts, and nerve guidance conduits.

Collagen is a significant constituent of the natural extracellular matrix. Collagen-based scaffolds have been used in a variety of applications due to a number of useful properties, such as haemostatic effect, low antigenicity and very good mechanical characteristics for use in soft tissue engineering applications. For this reason, it is known as the most promising material in tissue engineering applications owing to its excellent biocompatibility and biodegradability [2]. However, its fast biodegradation and low mechanical strength are the foremost issues that limit the further uses of this material.

Another extensively studied material is chitosan, a linear polysaccharide derived by partial N-deacetylation of chitin

\footnotetext{
*Author for correspondence (md_ionita@yahoo.com)
}

[3], which is the primary structural polymer in arthropod exoskeletons, shells of crustaceans or the cuticles of insects [4]. It possesses a unique biocompatibility, biodegradability, biological inertness, stability in the natural environment as well as antifungal and anti-bacterial properties [5-7].

In recent years, much attention has been paid to chitosanbased devices owing to their minimal foreign body reactions, intrinsic antibacterial nature biocompatibility, biodegradability and ability to be moulded into various geometries and forms, such as porous structures or membranes [8-10]. Moreover, chitosan and collagen have been reported as attractive candidates for scaffolding materials because they degrade as the new tissues are formed, without inflammatory reactions or toxic degradation [11].

$A L P$ is the common phosphatase in many organisms. For example, in humans, ALP is present in all tissues throughout the entire body. In clinical assay, ALP is considered as a biomarker for the diagnosis of many diseases, including bone diseases, liver dysfunction, prostatic cancer and bile duct blockage [12].

Glutaraldehyde (GA) is a bifunctional cross-linking reagent that can bridge amino groups between two adjacent polypeptide chains and has become the predominant choice in skin tissue engineering because of its water solubility, high cross-linking efficiency and low cost.

The recent data from scientific literature show the fact that, the biomaterials are given a special attention, namely 
to the enzyme immobilization on a variety of nanostructured materials: nanoparticles, nanofibres and hybrid nanocomposites [13].

The present study describes the fabrication of membranes consisting of biopolymer COL/CHI/ALP and their crosslinking with GA, with various concentrations. The degradation rate of collagen used in biomedical applications can be significantly altered by enzymatic pretreatment or cross-linking. In order to recommend biopolymeric membranes based on collagen-chitosan for tissue engineering, calcium adsorption was evaluated according to the Freundlich isotherm. As a novelty of the bioperformance characterization of the membranes, their haemocompatibility was evaluated thus leading to a more complete bioperformance investigation of membranes (including cell viability tests via MTT assay).

\section{Materials and methods}

\subsection{Materials}

The alkaline phosphatase (10-30 DEA unit $\mathrm{mg}^{-1}$ solid) is purchased from SIGMA, chitosan $(M=150,000$; D.D. = $84.5 \%$ ) from FLUKA, collagen type I bovine tendon, glutaraldehyde MERCK, 25\%. All the chemicals used in this work were of analytical grade and water was distilled.

\subsection{Preparation of chitosan gel (CHI)}

A $1 \%$ chitosan gel was prepared as follows: chitosan was dissolved in acetate solution, and the mixture was stirred with the magnetic agitator at $60^{\circ} \mathrm{C}$ till a homogeneous gel ( $\mathrm{pH}=5.4)$ was obtained.

\subsection{Preparation of collagen}

The gel (COL) was isolated from the bovine tendon by our original technology, National Institute of Research and Development for Biological Sciences, Bucharest, Department of Cellular and Molecular Biology [14].

The method to immobilize alkaline phosphatase on gel collagen-chitosan was by inclusion in the biopolymeric gel collagen-chitosan, and crosslinking with bifunctional agent GA at concentrations of $0.1,0.04$ and $0.08 \%$.

The two components of chitosan gel and collagen gel were mixed in $1: 1$ ratio $(\mathrm{v} / \mathrm{v})$, and alkaline phosphatase (5 $\mathrm{mg} \mathrm{ml}^{-1}$ ) was added with stirring in small amounts. Seven membranes COL/CHI/ALP/GA were prepared. The GA solution was prepared by diluting the initial solution of $25 \%$.

The mixture is poured into Petri enclosures. The obtained samples were dried in an oven at $37^{\circ} \mathrm{C}$ for $48 \mathrm{~h}$ and finally semi-transparent, elastic membranes were obtained.

The membranes obtained in Department of Biomaterials and Bioproducts were further tested in terms of biodegradation and biocompatibility based on methods established in the Department of Cellular and Molecular Biology from the Institute.

\subsection{Mineralization of membranes}

The $\mathrm{Ca}^{2+}$ adsorption on collagen membranes has been studied by other researchers by evaluating the biomineralization process $[15,16]$.

The membranes were cut into pieces of $1 \mathrm{~cm}^{2}$, dried at $30^{\circ} \mathrm{C}$ for $6 \mathrm{~h}$ and then were stored in desiccators at room temperature. The adsorption process was performed in flasks containing $250 \mathrm{ml}$ of simulated body fluids (SBFs) with ion concentrations $\left(\mathrm{Na}^{+} 213.0, \mathrm{~K}^{+} 7.5, \mathrm{Ca}^{2+} 3.8, \mathrm{Mg}^{2+}\right.$ 2.3, $\mathrm{Cl}^{-}$221.7, $\mathrm{HCO}_{3}^{-}$6.3, $\left.\mathrm{HPO}_{4}^{3-} 1.5, \mathrm{SO}_{4}^{2-} 0.8 \mathrm{mM}\right)$, nearly equal to those in human blood plasma, at $37^{\circ} \mathrm{C}$. The $\mathrm{pH}$ was maintained at 7.4 using tris (hydroxymethyl)-aminomethane $\left(\mathrm{CH}_{2} \mathrm{OH}\right)_{3} \mathrm{CNH}_{2}$ and $1 \mathrm{M} \mathrm{HCl}$. $\mathrm{Ca}^{2+}$ concentration in the solution was determined using ICP-MS. Each experiment was conducted in triplicates and the mean values were reported.

\subsection{Haemolytic study}

Haemocompatibility tests were performed according to ISO 10993-4 indications [17] studying the interaction of blood with the considered membranes.

The amount of haemoglobin released into the environment was determined relative to the total amount of haemoglobin in the blood sample [18].

Tests were performed using the Drabkin method, that is a method recommended by the International Standardization in Hematology for determining the concentration of haemoglobin in whole blood integral [19], knowing that Drabkin reagent oxidizes all kinds of haemoglobin to form stable cyanmethaemoglobin [20]. Samples of $2 \times 1 \mathrm{~cm}^{2}$ of the material of the study were incubated at $37^{\circ} \mathrm{C}$ for $72 \mathrm{~h}$ in CMF-PBS (calcium and magnesium free-phosphatebuffered saline).

Blood was collected from healthy volunteers by venipuncture Beckton-Dickinson in vacutainere containing sodium citrate $(3.8 \%)$ in the proportion of $9: 1$. After incubation in CMF-PBS, samples were placed in polypropylene, then $1 \mathrm{ml}$ of whole blood was added. The negative control and positive control were prepared by mixing $1 \mathrm{ml}$ of whole blood with $7 \mathrm{ml}$ of PBS and $7 \mathrm{ml}$ of distilled water, respectively. All the tubes were incubated for $3 \mathrm{~h}$ at $37^{\circ} \mathrm{C}$, shaking them by inversion every $30 \mathrm{~min}$ to ensure good contact between blood and as membranes. After incubation the tubes were centrifuged at $2000 \mathrm{rpm}$ for $15 \mathrm{~min}$.

The supernatant thus obtained is separated and then 20 $\mu$ was removed from each tube to be mixed with Drabkin reagent, the absorbance was read at $540 \mathrm{~nm}$ using an automatic spectrophotometer Chemwell.

The formula used to calculate haemolytic index (HI)

$$
\mathrm{HI}(\%)=\frac{\left(\mathrm{OD}_{\text {samples }}-\mathrm{OD}_{\text {negative control }}\right)}{\left(\mathrm{OD}_{\text {positive control }}-\mathrm{OD}_{\text {negative control }}\right)} \times 100 \text {. }
$$




\section{Results and discussion}

\subsection{In vitro biodegradation test}

The in vitro biodegradability of the membranes was evaluated using bacterial collagenase (Clostridium histolyticum, E.C. 3.4.24.3. SIGMA) [21,22].

The results indicate that the biodegradation of COL membranes in the presence of collagenase is significantly increased to values of $6.59 \%$ compared to the cross-linked samples (figure 1). From all the investigated samples, the COL-CHI-ALP-GA membrane with $0.08 \%$ GA has the smallest biodegradability.

\subsection{In vitro biocompatibility test}

The biocompatibility of the membranes is an important concern before proceeding to the in vitro study. There are numerous assays available to measure the cytotoxicity of the membranes, for example as water soluble tetrazolium salts
(WSTs), lactate dehydrogenase (LDH) and MTT assay. In the present study, biocompatibility was evaluated by MTT assay [23,24], this assay is based on the ability of cellular mitochondrial dehydrogenase to reduce the yellow-coloured tetrazolium salt to blue-coloured formazan crystals. Mouse fibroblast cells NCTC (L 929) were used in the experiment to measure the toxicity level of the prepared membranes. Cell viability of the membranes at different times (24 and $48 \mathrm{~h}$ ) is shown in figure 2 based on the optical density determined using spectrophotometric method.

Biocompatibility of a biomaterial refers to the extent to which the material does not have toxic or injurious effects on biological systems. Cell viability evaluation after 24 and 48 $\mathrm{h}$ in direct contact of the cells with the samples, registered a high biocompatibility for the studied samples, with viability ranging between 78.42 and $100 \%$.

Non-cross-linked membranes are biocompatible, and membranes cross-linked with low concentration GA, respectively, 0.04 and $0.08 \%$ are also biocompatible. However, high concentrations of GA lead to a decrease in the biocompatibility.

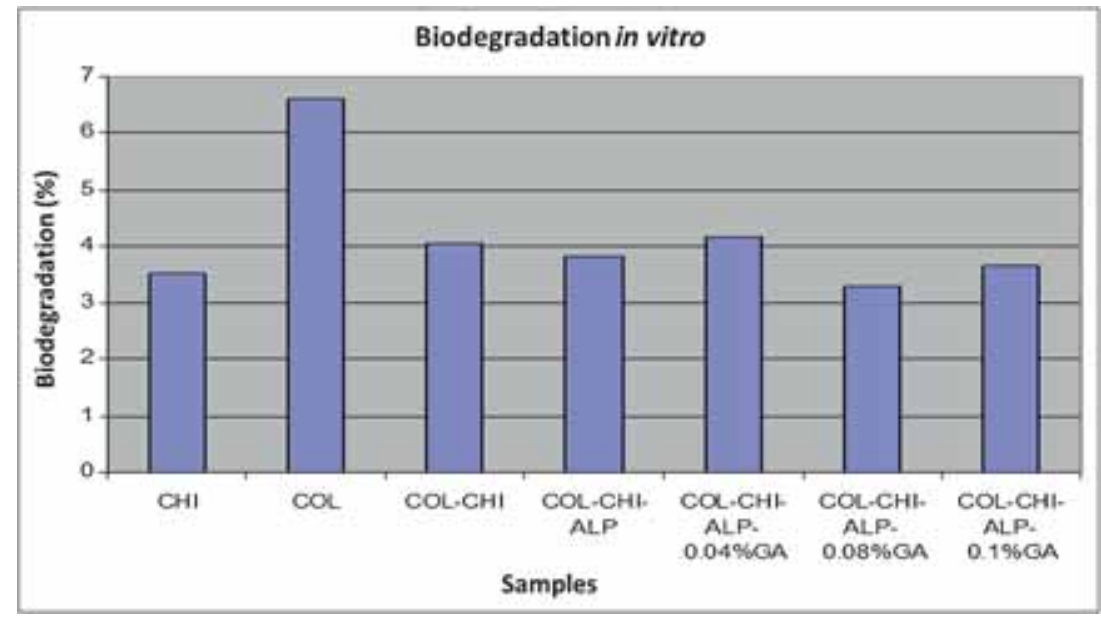

Figure 1. Biodegradability in vitro of the studied membranes.

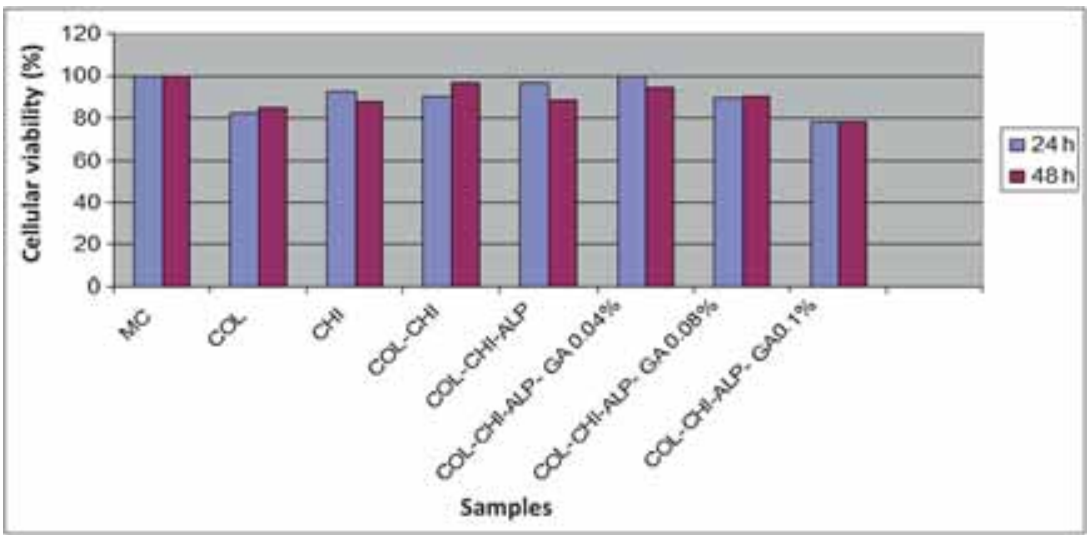

Figure 2. Cellular viability of membranes after 24 and $48 \mathrm{~h}$. 
The biological test for evaluating material cytotoxicity (cell viability) indicated that the studied membranes are nontoxic to testing cells. The viability of mouse fibroblast cells cultivated in the presence of COL-CHI-ALP-GA composites was higher than that of cells cultivated into the COL and CHI membranes (control). All studied membranes showed good biocompatibility.

The experimental data for all membranes demonstrate their potential for future application in tissue engineering.

\subsection{Cell morphology}

Experimental observations of the cell morphology after $48 \mathrm{~h}$ of culture have been emphasized by haematoxylin-eosin staining [25]. The characteristic morphological appearance consists of fibroblast fusiform round shape cells with circular core, 2-3 nucleoli, and fine grained intracytoplasmic. At $48 \mathrm{~h}$ of culture sowing cells are almost under confluence.

The cells used as a positive control $\mathrm{M}$ were treated with $\mathrm{H}_{2} \mathrm{O}_{2} \quad 0.003 \%$ in the culture medium and the expressed severe cytotoxic effects, resulted in the destruction of the substrate cell. The detached largely cells have been eliminated with the solutions used in the work-up method. The few remaining attached cells are small, the content is degraded and also intracytoplasmic cell morphology is different as can be seen in figure 3 .

The cells in contact with negative controls (represented by the membranes of type COL, CHI, COL-CHI and COLCHI-ALP) after $48 \mathrm{~h}$ of culture are presented in figure $4 \mathrm{a}-\mathrm{d}$, respectively, and the cell cultures have maintained the characteristic morphology of the fibroblast cell culture of type NCTC. Although the phase development of the culture is subconfluent, one can notice the non-cytotoxic character of both biomaterials and enzyme present in these membranes' composition. Furthermore, the favourable effect elicited by the COL-CHI-ALP membranes onto the NCTC culture is also observed, as the cellular proliferation is more evident when compared to the other membranes used as negative controls.

Cells in contact with the membrane type COL-CHI-ALPGA $0.1 \%$ (figure $5 \mathrm{a}$ ) after $48 \mathrm{~h}$ of incubation have a similar aspect as to the control of the culture (shown in figure $3 \mathrm{a}$ ), as the cells have the fibroblast specific NCTC form, but the cell density is lower than that of the control.

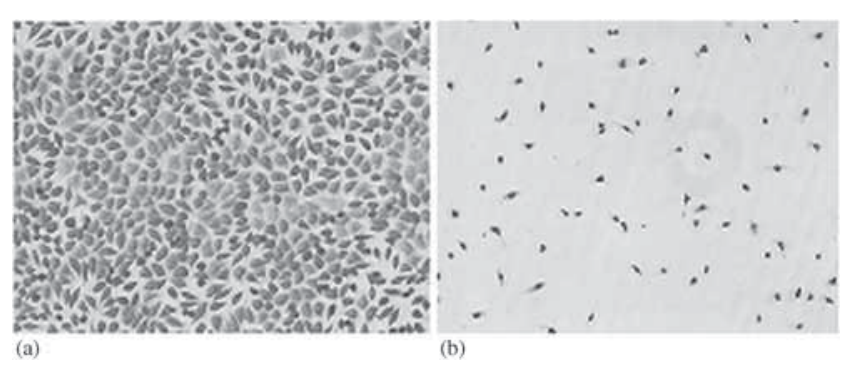

Figure 3. (a) Control cell culture NCTC $-48 \mathrm{~h}$ and (b) positive control: NCTC cell culture treated with $\mathrm{H}_{2} \mathrm{O}_{2}$ conc. $0.003 \%-48 \mathrm{~h}$.
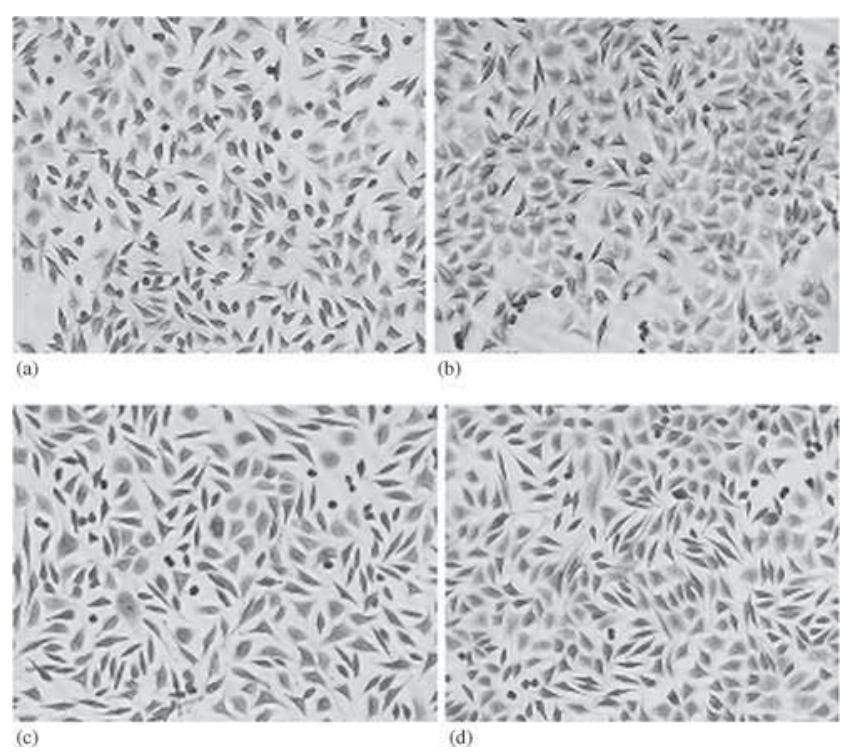

Figure 4. NCTC in direct contact with: (a) COL membranes, (b) $\mathrm{CHI}$ membranes, (c) COL-CHI membranes and (d) COL-CHIALP membranes for $48 \mathrm{~h}$.

Cells in contact with the membranes COL-CHI-ALPGA $0.08 \%$ and COL-CHI-ALP-GA $0.04 \%$ (figure $5 \mathrm{~b}$ and $\mathrm{c}$ ), after $48 \mathrm{~h}$ of incubation, have the typical aspect specific to NCTC fibroblasts and the cell culture is in a slightly subconfluent phase similar to that of the control culture. Additionally, a higher proliferation is observed for cells on membranes containing $0.04 \%$ GA (COL-CHI-ALP-GA $0.04 \%$ ) than on those with $0.08 \%$ GA (COL-CHI-ALPGA $0.08 \%$ ).

\subsection{Kinetic of membranes mineralization}

To examine the adsorption capacities of membranes, the dried membranes were added into SBF solution, then the flasks were stirred at $300 \mathrm{rpm}$ for $90 \mathrm{~min}$. The amount of Ca ions adsorbed per unit mass of membrane $\left(q_{\mathrm{e}}, \mathrm{mg} \mathrm{g}^{-1}\right.$ membranes) was obtained using

$$
q_{\mathrm{e}}=\frac{\left(c_{0}-c\right) V}{m \cdot 1000},
$$

where $c_{0}\left(\mathrm{mg} \mathrm{l}^{-1}\right)$ and $C\left(\mathrm{mg} \mathrm{l}^{-1}\right)$ are the concentrations of the $\mathrm{Ca}$ ions in the SBF before and after equilibrium, respectively, $V(\mathrm{ml})$ the volume of sorption medium and $m(\mathrm{~g})$ the weight of dry membrane.

The adsorption of $\mathrm{Ca}^{2+}$ onto all membranes is illustrated in figure 6. Rapid adsorption kinetics can be observed within the first $20 \mathrm{~min}$, while equilibrium was attained after $40 \mathrm{~min}$. The rapid metal adsorption kinetics in the membranes can be attributed to the strongly acidic and hydrophilic nature of the membranes caused by the presence of amine and hydroxyl groups which are responsible for interactions with the $\mathrm{Ca}^{2+}$ ions by electrostatic attraction. 


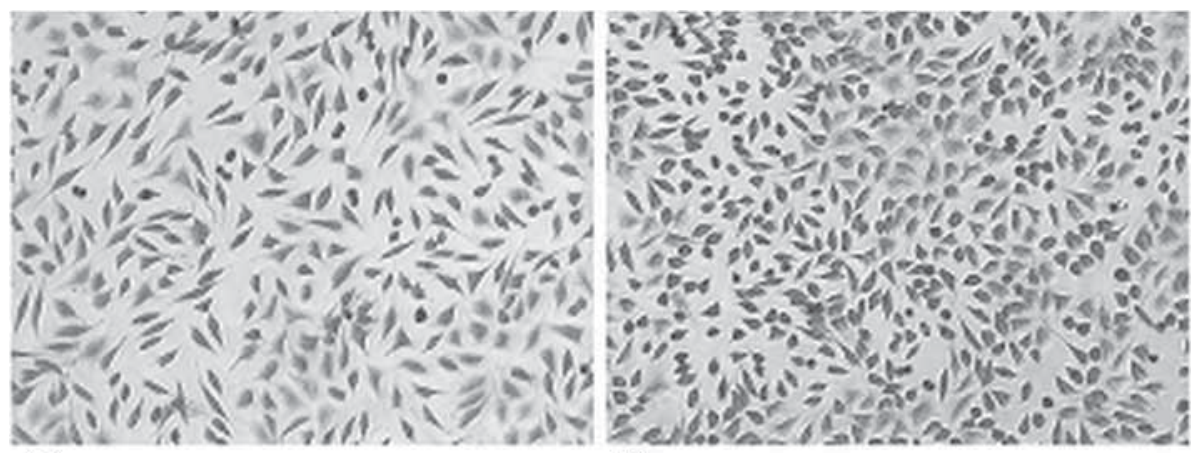

(a)

(b)

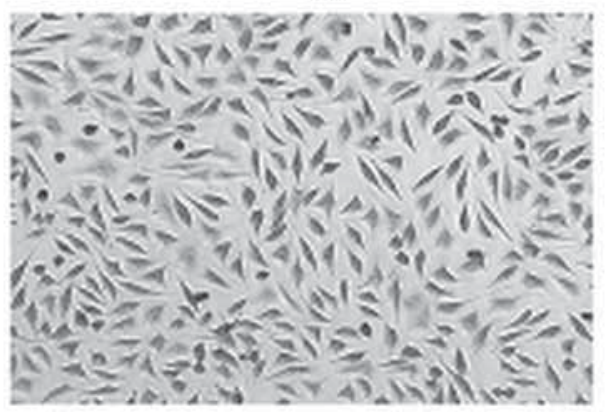

(c)

Figure 5. NCTC cell cultures in direct contact with the (a) membrane COL-CHI-ALP-GA $0.1 \%$ - 48; (b) membrane type COL-CHI-ALP-GA $0.08 \%-48 \mathrm{~h}$; and (c) membrane type COL-CHI-ALP-GA $0.04 \%-48 \mathrm{~h}$.

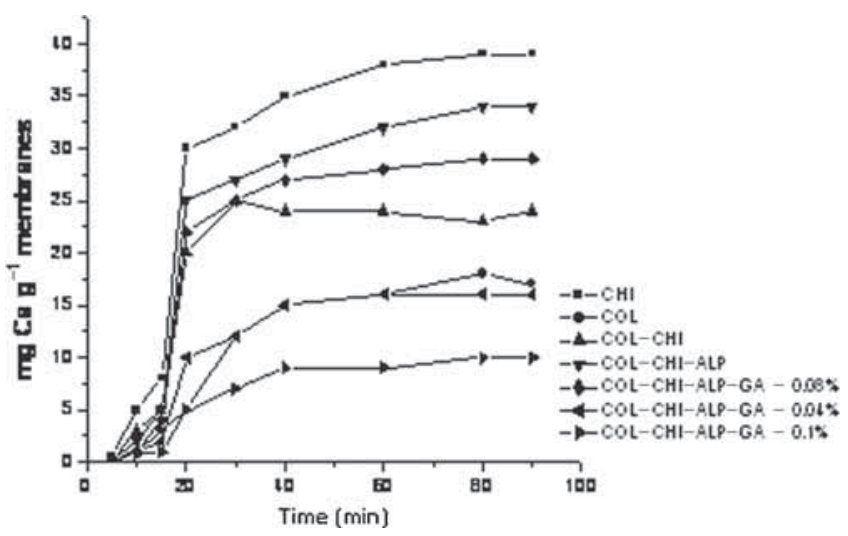

Figure 6. Evolution of $\mathrm{Ca} / \mathrm{g}$ membranes in time.

Moreover, it has been demonstrated that carboxyl groups are the major nucleation sites for collagen fibrils and that calcium ions can bind on the negatively charged carboxylate groups of collagen [26]. Li et al [27] indicated that the amino groups of chitosan could chelate calcium ion to form chitosan/calcium ion complexes.

The absorption capacity of $\mathrm{Ca}^{2+}$ ions was investigated in correlation with the variation in the initial $\mathrm{Ca}^{2+}$ ions in saturated SBF in the range $3.8-38 \mathrm{mM}$. After ICP-MS measurements, the results for $\mathrm{Ca}$ ions adsorbed per unit mass of membranes at equilibrium as a function of the concentration of $\mathrm{Ca}$ in saturated SBF are presented in figure 7.

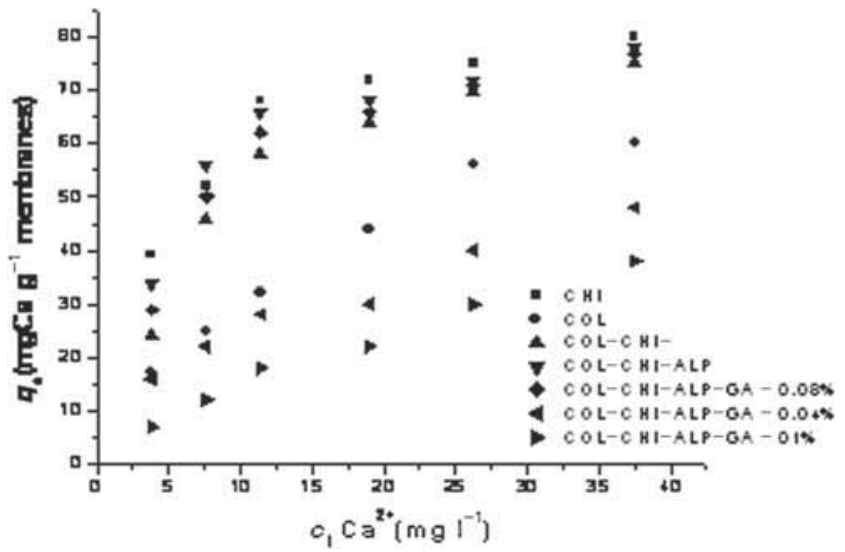

Figure 7. $\mathrm{Ca}^{2+}$ adsorbed/g membranes at equilibrium vs. $\mathrm{Ca}$ concentration in SBF.

To describe the adsorption process, the Freundlich adsorption isotherm was used, which is defined as

$$
q_{\mathrm{e}}=k c_{\mathrm{i}}^{1 / n},
$$

where $c_{\mathrm{i}}\left(\mathrm{mg} \mathrm{l}^{-1}\right)$ is the equilibrium concentration, $q_{\mathrm{e}}$ $\left(\mathrm{mg} \mathrm{g}^{-1}\right)$ the amount adsorbed per unit weight of adsorbent, $k$ the parameter related to the temperature, and $n$ the characteristic constant for the adsorption system $n>1$ shows good adsorption.

The plots of $\log q_{\mathrm{e}}$ against $\log c_{\mathrm{i}}$ and the regression equations of adsorption process are shown in figure 8 . 


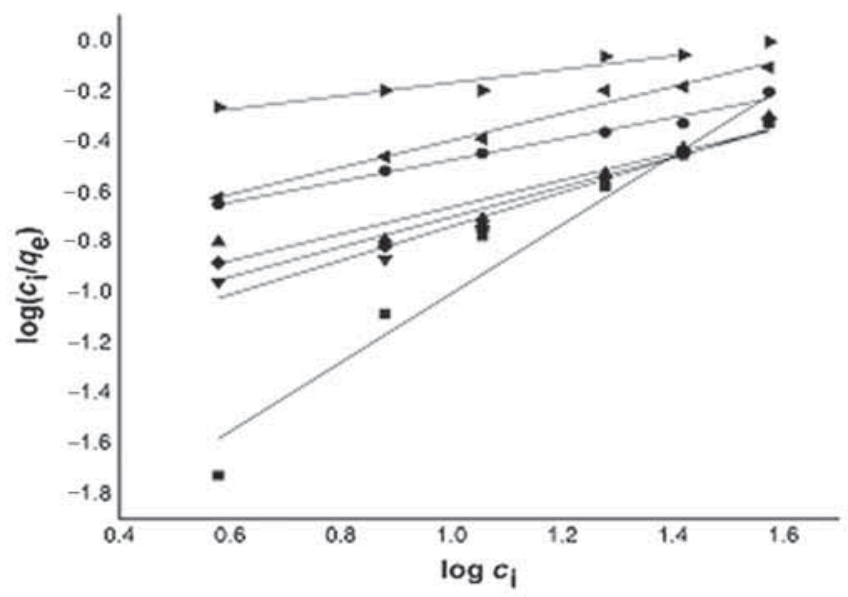

Regression equations of adsorption of studied membranes

\begin{tabular}{|l|l|}
\hline \multicolumn{1}{|c|}{ Sample } & \multicolumn{1}{c|}{ Parameters } \\
\hline CCHI & $y=2.372+1.367 x ; R=0.938$ \\
\hline CCOL & $y=-0895+0.421 x ; R=0.99$ \\
\hline COL-CHI-ALP & $y=-1.194+0533 x ; R=0.8994$ \\
\hline COL-CHI-ALP-GA $0.04 \%$ & $y=-1.414+0.676 x ; R=0.954$ \\
\hline COL-CHI-ALP-GA $0.1 \%$ & $y=-1295+0593 x ; R=0.931$ \\
\hline
\end{tabular}

Figure 8. Freundlich plots of membranes for $\mathrm{Ca}^{2+}$ removal.

Table 1. Freundlich parameters for the adsorbtion of $\mathrm{Ca}^{2+}$ onto membranes.

\begin{tabular}{lcc}
\hline Sample & $K$ & $n$ \\
\hline CHI & 235.504 & 0.731 \\
COL & 0.127 & 2.375 \\
COL-CHI & 0.063 & 1.876 \\
COL-CHI-ALP & 0.0385 & 1.479 \\
COL-CHI-ALP-GA 0.04\% & 0.0506 & 1.686 \\
COL-CHI-ALP-GA 0.08\% & 0.1169 & 1.872 \\
COL-CHI-ALP-GA 0.1\% & 0.370 & 3.773 \\
\hline
\end{tabular}

The Freundlich isotherm constants are listed in table 1. As can be observed, experimental data were nicely fitted to the Freundlich equation. Values of ' $n$ ' between 2 and 10 show a good adsorption [28].

\subsection{Haemolysis tests}

Haemolysis tests were conducted in triplicate and the average haemolytic index values are listed in table 2 .
Table 2. Haemolytic index.

\begin{tabular}{lcl}
\hline Membranes & Absorbance & HI $(\%)$ \\
\hline CHI & 0.025 & 3.894 \\
COL & 0.003 & 0.467 \\
COL-CHI & 0.24 & 3.72 \\
COL-CHI-ALP & 0.011 & 1.713 \\
CHI-COL-ALP-GA 0.04\% & 0.017 & 2.647 \\
CHI-COL-ALP-GA 0.08\% & 0.020 & 2.884 \\
CHI-COL-ALP-GA 0.1\% & 0.023 & 3.115 \\
\hline
\end{tabular}

The COL membranes have a haemolytic index below 0.5 , which categorizes it as non-haemolytic, but chitosan membranes are slightly haemolytic. Nevertheless, by adding collagen and ALP to chitosan, the haemolytic index decreases and the COL-CHI-ALP membrane is in the non-haemolytic domain (1.713 as compared to 3.894 for the CHI membrane). The COL-CHI-ALP-GA membranes have a haemolytic index greater than 2, so they are slightly haemolytic but less than the CHI membranes (containing only chitosan), so the additions of COL, ALP and GA lead to an improvement in the haemolytic properties of the membranes. 


\section{Conclusions}

On the basis of the experimental data obtained in the present work, the following conclusions can be drawn: the inclusion method is convenient for the immobilization of alkaline phosphatase on collagen-chitosan gel in order to elaborate different types of biocompatible membranes for the use in tissue engineering. The cell viability evaluation after 24 and $48 \mathrm{~h}$ of the cells in direct contact with the samples, registered viability ranging between 78.42 and $100 \%$.

The adsorption of $\mathrm{Ca}^{2+}$ onto all membranes could be described with the Freundlich isotherm. Regarding haemolytic index, by adding collagen and ALP to chitosan, the index decreases and the COL-CHI-ALP membrane is in the non-haemolytic domain. The cross-linked membranes (COL-CHI-ALP-GA) are slightly haemolytic with a haemolytic index greater than 2 ; however, these membranes present improved haemolytic properties compared to the chitosan membranes.

\section{Acknowledgements}

Berteanu wishes to thank The European Social Fund, Sectorial Operational Programme: Human Resources Development of the Romanian Ministry of Labour, Family and Social Protection through the Financial Agreement POSDRU/ID 132397.

\section{References}

[1] Nihuis A W, Van den Beucken J J, Boeman O C, Jansen J A and Leeuwenburgh S C 2013 Tissue Eng. Part C - Methods 19610

[2] Glowacki J and Mizuno S 2008 Biopolymers 89338

[3] Grolik M, Szczubiałka K, Wowra B, Dobrowolski D, Orzechowska-Wylègała B, Wylègała E and Nowakowska M 2012 J. Mater. Sci. Mater. Med. 231991

[4] Muzzarelli R A A 1977 Chitin (New York: Pergamon) 89

[5] Muzzarelli R A A 2009 Carbohydr. Polym. 771

[6] Kong M, Chen X G, Xing K and Park H J 2010 Int. J. Food Microbiol. 14451
[7] Tihan G T, Ungureanu C, Barbaresso R C, Zgârian R G, Rău I, Meghea A, Albu M G and Ghica M V 2015 C.R.-Chimie 18986

[8] Zhang K, Zhao M, Cai L, Wang Z, Sun Y and Qi H 2010 Chin. J. Polym. Sci. 28555

[9] Ungureanu C, Ionita D, Berteanu E., Tcacenco L, Zuav A and Demetrescu I 2015 J. Braz. Chem. Soc. 26458

[10] Kundu P, Jindal K S and Goswami K 2013 Bull. Mater. Sci. 36175

[11] Kim S B, Kim Y J, Yoon T L, Park S A and Cho I H 2004 Biomaterials 255715

[12] Li C M, Zhen S J, Wang J, Li Y F and Huang C Z 2013 Biosens. Bioelectron. 43366

[13] Li X, Cui R, Liu W, Sun L, Yu B, Fan Y, Feng Q, Cui F and Watari F 2013 J. Nanomater. 20131

[14] Negroiu G, Moldovan L, Caloianu M, Mirancea N and Mirancea D 1988 Rev. Roum. Biochim. 25143

[15] Xu S L A, Lin X, Liu H and Yonese M 2010 Chin. J. Chem. 281565

[16] Xu X R, Han J T and Cho K 2004 Chem. Mater. 161740

[17] Biological Evaluation of Medical Devices-Part 4: Selection of Tests for Interaction with Blood 1994 ISO 10990-4 (Geneva, Switzerland)

[18] Han V, Serrano K and Devine D V 2010 Vox Sang. 98116

[19] Zwart A, van Assendelft O W, Bull B S, England J M, Lewis S M and Zijlstra W G 1996 J. Clin. Pathol. 49271

[20] Balasubramaniam P and Malathi A J 1992 Postgrad. Med. 388

[21] Moldovan L, Oancea A, Oprita E I, Balan M and Zarnescu O 2009 Roum. Biotechnol. Lett. 144459

[22] Lloyd A W 2002 Med. Device Technol. 1318

[23] Berridge M V, Tan A S, McCoy K D and Wang R 1996 Biochemica 1414

[24] Mosmann T 1983 J. Immunol. 6555

[25] Avwioro G 2011 JPCS 124

[26] Kikuchi M, Itoh S, Ichinose S, Shinomiya K and Tanaka J 2001 Biomaterials 221705

[27] Li B, Wang Y, Jia D and Zhou Y 2011 J. Biomater. Sci. Polym. 22505

[28] Panday K K, Prasad G and Singh V N 1985 Water Res. 19869 